\section{LA CASACIÓN: DE RECURSO EXTRAORDINARIO A PROCESO CONSTITUCIONAL DE LA SENTENCIA PENAL A PARTIR DE SUS FINES*}

\author{
THE CASSATION APPEAL: FROM EXTRAORDINARY \\ RESOURCE TO CONSTITUTIONAL PROCESS OF \\ CRIMINAL SENTENCE BY ITS PURPOSES
}

\author{
A CASSAÇÃO: DE RECURSO EXTRAORDINÁRIO \\ PARA PROCESSO CONSTITUCIONAL DA \\ SENTENÇA PENAL, A PARTIR DOS SEUS FINS
}

\title{
RESUMEN
}

El presente escrito, complementario de los anteriores de esta misma publicación académica, constituye una mirada sobre el recurso de casación a través de la historia legal hasta su conversión en auténtica modalidad de acción constitucional como pieza procesal defensora de los derechos fundamentales de los sujetos procesales al interior del trámite penal en clara señal de reconocimiento a la dignidad humana, contemplada en el artículo 1 de la Carta como fundamento del Estado Social de derecho.

De esta forma el lector testimoniará el punto de encuentro entre la vieja dogmática jurídico penal y el nuevo concepto del derecho frente a la necesidad de un derecho, no apenas sancionador sino

\footnotetext{
* Artículo de investigación producto del trabajo de grado: "Los fines de la casación son el fundamento filosófico del recurso", con que el autor obtuvo Mención de honor por la Universidad La Gran Colombia, sede Bogotá, como requisito para obtener el grado de Especialista en Casación Penal en 2004.

a. Bachiller egresado del Colegio Agustiniano Norte de Bogotá, abogado de la Universidad Externado de Colombia, especialista en Ciencias penales, en Criminología de la misma Universidad, Especialista en Casación Penal de la Universidad La Gran Colombia, , Maestría en Filosofía Latinoamericana de la Universidad Santo Tomás de Bogotá, Doctorando en Filosofía de la misma Universidad. Decano de la Facultad de Derecho de la Universidad Pública Colegio Mayor de Cundinamarca y director de la Revista Misión Jurídica. Profesor de Filosofía del derecho, deontología jurídica y derecho penal en Pregrado y posgrado. Investigador. Excandidato a Magistrado de la Sala de Casación Penal de la Corte Suprema de justicia.
}

Ricardo Martínez Quintero a

rmartinezq@unicolmayor.edu.co Fecha de recepcion: 1 de Diciembre 2010

Fecha de revisión: 23 de Mayo 2011

Fecha de aceptación: 15 de Julio 2011

\footnotetext{
MISIÓN JURÍDICA

Revista de Derecho y Ciencias Sociales Bogotá, D.C. (Colombia)

Colaboradores Externos Internacionales Núm. 6, Año 2013

enero-diciembre, pp. 259-272.

SSN 1794-600X
} 
claramente garantista, en un mundo donde la imagen de la justicia no solo deriva de la aplicación de las normas, sino también y por excelencia, de los valores y principios que, otrora fuera de las posibilidades en la administración de justicia, ahora son innegociables, impostergables e ineludibles en el ejercicio de esa función pública.

Situación que compromete deontológicamente a la totalidad de los sujetos imbuidos en los trances de la justicia penal, de tal forma que la pedagogía pasa de ser una ilusión a una realidad por necesidad.

\section{PALABRAS CLAVES}

Constitución Política, recurso de casación, justicia, deontología, axiología, procedencia, acción, legalidad, valores, principios.

\section{ABSTRACT}

This letter complements previous academic publication of the same, is a look at the appeal through the legal history until its conversion into real mode of action as a procedural piece constitutional defender of fundamental procedural rights subject to inside the criminal process in a clear sign of recognition of human dignity under Article 1 of the Charter as the foundation of the rule of law.

In this way the reader will testify the meeting point between the old dogmatic criminal law and the new concept of the right against the need not just penal law but clearly guarantees in a world where the image of justice not only derived from the application standards and excellence but also the values and principles that once out of the question in the administration of justice, now non-negotiable, ineluctable and inescapable in the exercise of their public functions.

Deontologically compromising situation to all subjects imbued with the criminal justice trances so that pedagogy goes from being an illusion to reality by necessity.

\section{KEYWORDS}

Political Constitution, Cassation Appeal resource, justice, deontology, axiology, origin, action, legality, values, principles.

\section{RESUMO}

O presente documento, complementando os anteriores desta mesma publicação acadêmica, representa um olhar sobre o recurso da cassação ao longo da história jurídica até sua conversão em modo real de ação constitucional como ato processual defensor dos direitos fundamentais dos sujeitos processuais, dentro do processo penal, como um sinal claro do reconhecimento da dignidade humana, contemplada no artigo 1 da Constituição como estabelecimento do Estado Social de direito.

Desta forma, o leitor irá testemunhar o ponto de encontro entre o Direito Penal dogmático, conservador e o novo conceito de Direito, frente à necessidade de um Direito não apenas punitivo, mas principalmente assegurador, num mundo onde a imagem da justiça não só é derivada da aplicação de normas, mas também dos valores e princípios que outrora foram tema da administração da justiça e agora são inegociáveis, inevitáveis e inescapáveis no exercício dessa função pública.

Situação que compromete deontologicamente todos os sujeitos imbuídos em ações de justiça criminal, de modo que a pedagogia deixa de ser uma ilusão para ser uma realidade por necessidade.

\section{PALAVRAS-CHAVE}

Constituição, recurso da cassação, a justiça, a ética, a axiologia, origem, ação, direito, valores, princípios.

\section{INTRODUCCIÓN}

El derecho positivo, por naturaleza, está llamado a los cambios, entendidos estos como las variantes que dentro del discurrir de la historia debe soportar a costa de verse expuesto a la pérdida de credibilidad en todo sentido: científico, social, ético etc. De ahí que el paradigma del Estado Constitucional de Derecho muestre la justicia constitucional como la encargada de denotar esa nueva cara con la que el derecho afronta una realidad inocultable; lo que hace evidente, con la defensa de la supremacía constitucional dentro del sistema de fuentes del derecho, la tutela de los derechos humanos consagrados en la Carta Mayor, como en la Convención Americana, reparando a 
las víctimas por la responsabilidad internacional del Estado ${ }^{1}$

Hecho que deja en claro el porqué del impacto padecido al interior del sistema jurídico colombiano con base en la Constitución de 1991 no se limitó a las consecuencias producidas por el accionar de los ciudadanos, a través de la tutela o las acciones de grupo, sino que así haya sido a paso más lento que el pensado. Institutos de vieja tradición procesal, como el recurso extraordinario de casación y la misma acción de revisión, también reseñan las transformaciones a las que con motivo de la justicia constitucional ha venido siendo inmediata la sociedad nacional en las dos últimas décadas.

Con este introito aspiramos en los siguientes renglones demostrar la simbiosis a la que ha sometido el legislador históricamente al recurso extraordinario de casación, hasta llegar hoy en día a ser un verdadero juicio constitucional de la legalidad de una sentencia proveniente de instancias. Con lo cual queda clara la superación de la mera exigencia técnica para darle paso a una nueva estructura del recurso con cimiento en sus fines, es decir, el objetivo propósito de la defensa de los derechos fundamentales de los ciudadanos en detrimento de los factores que otrora lo imposibilitaron de ser un mecanismo latamente protector de aquellos derechos puntualmente consignados en la Constitución actual. Los fines de la casación como fundamento filosófico del recurso, de tal manera que en desarrollo de la alzada se patentiza un proceso de carácter netamente constitucional tanto por la rigurosidad exigida al Tribunal Especial como su responsabilidad social en el constructo del Estado, planteado por el constituyente en el artículo 1 de la Carta Política.

\section{PROBLEMA DE LA INVESTIGACIÓN}

La historia es posible verla desde alternos puntos de vista, incluso sin prejuicios llegar a considerarla como siempre justa a pesar de las diferencias entre unos y otros que siendo los mismos por referencia al objeto son distintos.

Es lo que planteamos en esta nueva excursión intelectual en la que la procedencia del recurso de

1 Derecho procesal constitucional, toma IV, Editores Ltda. Libro resultado de investigación. Pág. 130. casación siempre lo muestra como una garantía pero que, dependiendo de la forma política de la época, tal asunto trascendental muestra pocas semejanzas comparativamente.

Ejercicio que conduce, en primer lugar a ubicar el recurso en el marco histórico, luego a interpretarlo y finalmente conocerlo en sus esencias. Con ello es posible descubrir cómo, en efecto, lo que por ejemplo se consideraba distante de la posibilidad de ser conocido por todos, - en especial por la fuerza del positivismo - paso a ser un tema de reflexión general por su compromiso frente a la consolidación de los derechos fundamentales consagrados en la Constitución Política de 1991.

Llegar al momento histórico del garantismo de los derechos fundamentales demandó un proceso histórico de la humanidad, en especial en países como el nuestro en el que la inmensa mayoría de los ciudadanos esperan no ver quebrantada la confianza que han depositado en sus servidores públicos; quienes deben ejercer con ética personal, interpersonal e impersonal, haciendo protuberante con la obra que es posible la construcción del Estado Social de derecho.

Situación reseñada atrás, que ahora permite decir sin ambages que cuando la justicia se administra con la mera legalidad, no es lo mismo que administrarla bajo el control de los valores, las virtudes y los principios que son obligación de la criatura humana de acuerdo con los roles que desempeña al interior de la sociedad.

\section{METODOLOGÍA}

Esta investigación se incrusta en una general que el autor realizó desde el año 2004 como estudiante y docente en la Especialización de Casación Penal en la Universidad La Gran Colombia, casa de estudio que ha acogido y residenciado al suscrito con amos académico desde hace 25 años. Esta tarea que se ha venido incrementando en nuevos ámbitos, espacios y sobre nuevos subtemas. En la Universidad Santo Tomás de Bogotá, en la Universidad Colegio Mayor de Cundinamarca y respecto de las pretendidas reformas al recurso. En su trámite, su desenvoltura, sus incidencias etc.

Por eso en lo que aquí respecta se aprovecha lo expuesto por el legislador tratándose de la 
procedencia del recurso de casación hasta llegar a darle su importancia pero a partir de sus fines. Clara demostración de su injerencia en la concepción de la nueva mirada sobre el derecho en su fórmula garantista frente a postulados como el del equilibrio, la igualdad, la imparcialidad, la confianza pública etc.

Colofón de lo anterior, este trabajo es de corte histórico legal descriptivo que busca el permanente juicio crítico del lector, pero también de corte propositivo en la medida en que elevamos algunas sugerencias desde el ámbito de la academia, lugar desde el que se considera deben promoverse gran parte de las ideas referenciales para hacer posible la mejor labor de los legisladores.

Se concluye entonces con la comprobada tesis del favor de las metodologías mixtas como expresión del pluralismo epistemológico como fundamento del nuevo concepto del derecho garantista.

\section{BREVE SINOPSIS SOBRE LOS FINES DEL PROCESO PENAL EN COLOMBIA}

En el Decreto 409 de 1971 norma alguna hacía referencia a los fines del proceso, menos a los de la casación. En el Decreto 0050 de 1987 aparece como principio rector, el de la finalidad del procedimiento, artículo 11 así:

"En la interpretación de la ley procesal, el juez deberá tener en cuenta que la finalidad de procedimiento es la efectividad del derecho material y de las garantías debidas a las personas que en él intervienen".

En el Decreto 2700 de 1987 artículo 219 se lee: "Fines de la Casación. El recurso extraordinario de casación tiene por fines primordiales la efectividad del derecho material y de las garantías debidas a las personas que intervienen en la actuación penal, la reparación de los agravios inferidos a las partes en la sentencia recurrida, y la unificación de la jurisprudencia nacional".3

2 ORTEGA TORRES. Código Penal y Código de Procedimiento Penal. Temis. Bogotá, D.C. 1988. Pág. 124.

3 Nuevo Código De Procedimiento Penal, Edición actualizada. 2003. pág. 232.
En la ley 600 de 2000 Artículo 206 "Fines de la casación. La casación debe tener por fines la efectividad del derecho material y de las garantías debidas a las personas que intervienen en la actuación penal, la unificación de la jurisprudencia nacional y además la reparación de los agravios inferidos a las partes con la sentencia demandada".

En el proyecto de ley estatutaria, ya un hecho legislativo a través de la Ley 906 de 2004 se puede leer:

Artículo 174. Finalidad. El recurso pretende la unificación de la jurisprudencia, la efectividad del derecho material y de las garantías de los sujetos procesales; y la reparación de los agravios inferidos a aquellos.

Artículo 175. Procedencia. El recurso como control constitucional y legal procede contra las sentencias absolutorias y condenatorias proferidas en segunda instancia en los procesos adelantados por delitos, cuando afectan derechos o garantías fundamentales por:

1. Falta de aplicación, interpretación errónea, o aplicación indebida de una norma del bloque de constitucional o legal, llamada a regular el caso.

2. Desconocimiento sustancial de la estructura del debido proceso por afectación trascendente de su estructura o de la garantía debida a cualquiera de las partes.

3. El manifiesto desconocimiento de las reglas de producción y apreciación de la prueba sobre la cual se ha fundado la sentencia ${ }^{5}$.

En la ley 906 de 2004 en definitiva quedó:

Artículo 180. Finalidad. El recurso pretende la efectividad del derecho material, el respeto de las garantías de los intervinientes, la reparación de los agravios inferidos a estos, y la unificación de la jurisprudencia.

Artículo 181. Procedencia. El recurso como control constitucional y legal procede contra las sentencias proferidas en segunda instancia en los procesos adelantados por delitos, cuando afectan derechos o garantías fundamentales por:

4 CADENA LOZANO, Raúl. Código Penaly Código de Procedimiento Penal. (Concordados y actualizados suplemento legislativo). 3 Ed. 1996. pág. 203.

5 Proyecto De La Ley Estatutaria. Pág. 52. 
1. Falta de aplicación, interpretación errónea, o aplicación indebida de una norma del bloque de constitucionalidad, constitucional o legal, llamada a regular el caso.

2. Desconocimiento del debido proceso por afectación sustancial de su estructura o de la garantía debida a cualquiera de las partes.

3. El manifiesto desconocimiento de las reglas de producción y apreciación de la prueba sobre la cual se ha fundado la sentencia.

4. Cuando la casación tenga por objeto únicamente lo referente a la reparación integral decretada en la providencia que resuelva el incidente, deberá tener como fundamento las causales y la cuantía establecidas en las normas que regulan la casación civil ${ }^{6}$.

\section{LOS FINES DE LA CASACIÓN SON EL FUNDAMENTO FILOSÓFICO DEL RECURSO}

El recurso extraordinario de casación, no como herramienta de poder o afines, sino como una conquista universal del sentir revolucionario Francés que linderó territorios entre el absolutismo del soberano y la protección de la norma objetiva, sin reveses en su interpretación genuina, permite afirmar que la casación es el medio a través del cual se rompe la sentencia o se profliga el proloquio que reprobó el examen de legalidad constitucional o sustancial, dando al traste con el IUS CONSTITUTIONIS y el IUS LITIGATORIS. Elementos integrados iura que, deben ser las finalidades de la casación frente al modelo constitucional actual. Aunque éste es un argumento obiter dictum necesarísimo expresarlo así, primero para argumentar con solvencia desde un principio el trabajo y, segundo, porque para nadie es secreto que cuanto menor sea la protección al litigante que resguarda su actitud en la Carta Política, menor será la protección de la norma. No referimos a cualquier norma, lo hacemos en torno a la constitucional prevista en el artículo 230 - ejusdem-.

Así las cosas, no discutimos de entrada la cuota técnica que debe llevar una demanda de casación, tampoco que el recurso constituye un juicio de legalidad y menos la competencia atribuida a la Corte Suprema de Justicia en su Sala Penal. Lo que fue fundamento filosófico del recurso, en otra época, con base en una Constitución determinada - republicana - y en una norma de restricción, no

6 Código procedimiento penal actualizado. 2011. puede serlo de manera inamovible en una distinta, con orientaciones diversas y, menos, cuando de la normatividad vigente no fluyen expresiones literales en tal sentido.

Quiero significar entonces la importancia que para estos efectos académicos debe tener la labor permanente de producción de ideas, gestión sanamente aislada de otros escenarios, en los que distinto a reflexionar, se tejieron las marañas inadhesivas al mundo ius filosófico. Por ello entrecomillo dos interesantes acápites de textos relacionados con el asunto:

Desde que está sobre la tierra, el hombre se pregunta por su destino y busca las razones y el fundamento de su propio ser: esto es justamente la filosofía, la expresión de ese continuo interrogante. Todavía subsiste el prejuicio de que la filosofía se ocupa de problemas que no tienen nada que ver con la realidad de la existencia humana, y de que permanece encerrada en una esfera lejana $e$ inaccesible donde no llegan los deseos ni las necesidades de los hombres $Y$ junto a ese, existe otro prejuicio: el de que la filosofía es un conjunto desconcertante de opiniones superpuestas que se contradicen, sin un auténtico hilo conductor que sirve de orientación para los problemas de la vida. Ambas ideas son erróneas: en realidad, nada que sea humano resulta ajeno a la filosofía, porque ésta es la reflexión del hombre que se busca a sí mismo. Y en tal reflexión, todos los pensamientos sinceros y coherentes son importantes, tanto los antiguos como los modernos. Porque en la filosofía no ocurre como en la ciencia, donde los últimos descubrimientos anulan a los anteriores. En el mundo de las ideas, una reflexión que viene del pasado, si ha sido verdadera, es fuente permanente de enseñanza y vida: ya que en la historia de la filosofía las sucesivas doctrinas no son más verdaderas que las que les precedieron. Todas resultan importantes, aunque su voz llegue debilitada por el tiempo, como expresión de hombres solidarizados por una investigación común. Se trata pues de prejuicios injustos, basados en las falsas apariencias y el desconocimiento. Convencidos de estos, y de la enorme importancia que tiene el tema, hemos planteado esta obra para contribuir a deshacerlos, difundiendo la historia de la filosofía entre los no filósofos ${ }^{7}$.

7 Introducción a la filosofía. Segel Michelin Pastor. Academia Ministerial Logos. 
Complementa el aserto RUBÉN JARAMILLO VELEZ, en su obra "Problemática actual de la Democracia":

Pero, además, en Grecia había aparecido la Polis. En la Grecia Clásica se había realizado una experiencia ética absolutamente innovadora, la sociedad ya no estuvo organizada exclusivamente alrededor del monarca, en torno al déspota, ya la Polis se caracterizaba por el uso público de la razón para recordar la noción kantiana a que hicimos alusión al comienzo. Y por ello fue en las ciudades griegas en donde surgió la filosofía, tal como lo revela un término cardinal del lenguaje filosófico: "categoria".

Tiene que ver con el "ágora", la plaza pública en el centro de la ciudad, por provenir del verbo kat agoreo, que significa "decir algo en el ágora, acusar públicamente en el ágora" (la noción proviene del lenguaje judicial).

La existencia del ágora implicaba esa experiencia ética de la ciudadanía. La Polis tenía como centro el ágora, ya no el palacio real, ya no la residencia del déspota. En efecto, aquella era el lugar en donde se reunían los ciudadanos y fue en la Polis, primero en el Asía menor y luego en la metrópoli, en donde nació la filosofía. Por lo cual se identifica al primer filósofo con un locativo: lo llamamos TALES DE MILETO ${ }^{8}$.

Sobre la casación, parto del presupuesto que siempre ha tenido su fundamento filosófico en las razones de Estado, sólo que de acuerdo con la nueva concepción del mismo, a partir de 1991, este es social de derecho, de donde surge inconcuso que los derechos fundamentales sancionados por la Constitución deben ser garantizados y concretamente satisfechos. Dice FERRAJOLI :

"El garantismo, bajo este aspecto, es la otra cara del constitucio-nalismo, dirigido a asegurar las técnicas de garantía idónea para tener a su vez el máximo grado de efectividad a los derechos constitucionalmente reconocidos. $Y$, además, en el sentido en que el paradigma de la democracia constitucional es todavía un paradigma embrionario, que puede y debe ser extendido en una

8 JARAMILLO VELEZ, Rubén. Problemática actual de la democracia. Jurídicas G. Ibáñez C. Ltda. Bogotá, D.C. 2004. pág. $57-58$. triple dirección: en primer término, en garantía de todos los derechos, no sólo de los derechos de libertad sino también de los derechos sociales; en segundo lugar, en confrontación con todos los poderes, no sólo los poderes públicos sino también los poderes privados; en tercer lugar, a todos los niveles, no sólo del derecho estatal sino también del derecho internacional.

Se trata de tres expansiones, todas igualmente indispensables, del paradigma garantista y constitucional heredado de la tradición. Este paradigma que, como sabemos, nació como tutela de los derechos de libertad, ha sido ordenado como sistema de límites sólo a los poderes públicos y no así a los poderes económicos y privados, que la tradición liberal ha confundido con los derechos de libertad; y ha permanecido anclado en los confines del Estado nación. El futuro del constitucionalismo jurídico, y con él el de la democracia, está, por el contrario, confiado a ésta, su triple articulación y evolución: hacia un constitucionalismo social, añadido a aquel liberal, hacia un constitucionalismo de derecho privado, añadido a aquel de derecho público; hacia un constitucionalismo internacional, añadido a aquel estatal ${ }^{9}$.

Algo de lo que no puede apartarse la casación, prima facie porque el sistema no destila por el Gobierno de los jueces y, segundo, por el dato histórico legal que muestra el tratamiento dado por el legislador al recurso, hasta abordar hoy en una idea según la cual para la procedencia y real efectividad del mismo lo que impera son los fines y no las antes causales cimentadas en criterios de inflexibilidad y por qué no decirlo, de capricho legislativo a la postre conculcador de las razones que deben inspirar una justicia material consonante con las esencias filosóficas de cualquiera de las escuelas que durante los siglos han teorizado sobre el tema. Por eso los hoy determinados fines de la casación fueron desprendidos de una norma inicialmente concebida como principio rector del procedimiento penal -1987-, luego norma rectora del mismo. Preceptos inspirados filosóficamente por la Carta Política de 1886.

9 FERRAJOLI, Luigi. El garantizo y la filosofía de derecho. Departamento de publicaciones de la Universidad Externado de Colombia. Bogotá, D.C. 2000. pág. 177 - 178. 
El tema no es fácil, sobre él Díez Ripollés, en su trabajo La racionalidad de las leyes penales apunta:

Tampoco se entiende por qué unos derechos fundamentales prejurídicos, que configuran el Estado de derecho y condicionan el derecho moderno, sólo pueden desenvolverse como un conjunto de principios coherentes en la medida en que estén amparados por el principio de legalidad; pareciera que, pese a los reclamos en sentido contrario, la legislación interna tuviera la primacía frente a la externa.

Mi tesis es que la relevancia otorgada a ambos principios, de formalización y legalidad, refleja, una vez más, dos limitaciones omnipresentes en la reflexión fundamentadora del derecho penal. La primera de ellas es la tendencia a razonar desde el derecho positivo, el temor al vacío que suscita toda propuesta fundamentadora que no puede contar con un texto legal que la soporte. La segunda, en estrecha relación con la anterior, es la persistencia, pese a las apariencias, de una actitud defensiva en la configuración de los principios jurídicopenales, que lleva a que lo determinante sea cómo logramos frenar la intervención penal, y no cómo hay que legítimamente configurarla.

Enunciado que comparto, más cuando el mismo autor luego de señalar los principios que en su opinión deben regir el modelo estructural de la racionalidad ética penal: protección, lesividad esencialidad o fragmentariedad, interés público correspondencia con la realidad, responsabilidad, imputación, reprochabilidad, jurisdiccionalidad, sanción, humanidad de las penas, teleológico proporcionalidad, monopolio punitivo estatal; incluye el de la certeza o seguridad jurídica, pero no como el que pueda valerse por sí sólo, sino en conjunto con los otros ${ }^{10}$.

De tal manera no es correcto apreciar la seguridad jurídica como la que deviene únicamente como producto de la legalidad formal, sino toda aquella procedente del juicio racional que permitió a los funcionarios el enlace lógico, coherente de todos los principios atrás reseñados. Eso sí, con el referente constitucional.

Por lo anterior, respetuosamente creo, La Corte Suprema de Justicia en principio restringió por fuerza de costumbre legal su labor de juez

10 DÍEZ RIPOLLÉS, José Luis. Práctica y teoría la racionalidad de las leyes penales. Trotta. Bogotá, D.C. 2003. pág. 135 - 136. de casación al contenido literal del artículo 206 del C.P.P. que establece los fines del recurso efectividad del derecho material y de las garantías debidas a las personas que intervienen en la actuación penal, la unificación de la jurisprudencia y la reparación de los agravios inferidos a las partes con la sentencia demandada - sin perjuicio de lo dispuesto en el 216 ejusdem en el sentido de la viabilidad de la ruptura del fallo cuando avisa el paginario la afectación de las garantías fundamentales. Sin embargo, itero, en mi opinión, lo que apareció reglado como excepción, de acuerdo con el texto constitucional, fue lo que debió operar como regla. Es decir, no podía la Corte casar sentencias solo cuando era ostensible el atentado contra las garantías fundamentales, sino que "debió" casarlas. La aplicación del patrón deontológico proveniente de la Constitución, la cual, no se olvide, plasma el debido proceso como derecho fundamental de imperativa observancia tanto en los trámites administrativos como judiciales.

Entonces, con todo y la miopía del Legislador al redactar la Ley 600 de 2000, dejando de costado la mención de los derechos fundamentales para en su lugar poner frente a los ojos del lector el aserto "Garantías fundamentales", no significa que todos aquellos casos que bien pudieron ser objeto de protección de los derechos fundamentales y dejaron de serlo, hubieran roto el principio de seguridad jurídica en detrimento de la imagen del máximo Tribunal de la Justicia Ordinaria. Por lo demás, esta cuestión, sin duda, fue el detonante del enfrentamiento entre las altas Cortes durante la década pasada.

En consecuencia, pese a todo, resulta incontrastable que los fines de la casación inicialmente previstos en el artículo 206 de la Ley 600 de 2000, ahora en el precepto 180 de la Ley 906 de 2004- son el fundamento filosófico de recurso. Lamentablemente como suele ocurrir en esta clase de tránsitos legales ideológicos Colombia no es la excepción y más allá de que la mentada norma haya empezado a ser elaborada con evidentes timideces desde 1987, como se vio, nuestra cultura jurídica no ha permitido de lleno el ingreso al medio de la aplicación del principio de estricta legalidad, como tampoco el criterio constitucionalista, el cual abre líneas de avance hacia el modelo de Estado previsto por la Carta. 
Empero, con el nuevo diseño escriturario del procedimiento penal, se espera emerja en todas las decisiones de casación el criterio constitucionalista, ese de apertura a la humanización del derecho, dentro de cuyo patrimonio filosófico se encuentran los postulados de emancipación facilitadores del ingreso a la administración de justicia, entre otros, del elemento principal de la custodia de los derechos fundamentales, sin el cual resulta imposible la implantación efectiva del Estado Social de derecho. Aserto que por su virtualidad, impone la adhesión en los fallos de las notas de supralegalidad, las que precisamente por no desprender de contenidos preceptivos de lectura taxativa, invitan a los administradores de justicia a concebir la validez del juicio racional y de aceptación general en su diario fungir, dimanando con ello hacia la sociedad, el resplandor efectivo de la Carta fundamental.

En consecuencia si la Constitución en su estructura antropocéntrica clama por la libertad con el báculo de la autoridad, resulta a todas luces inconveniente que con ella se pretexte la mera legalidad para fallar en casación. Al contrario, siendo la orientación constitucional, receptáculo de valores, ojalá sean estos, no otros, los que garanticen y fijen la aplicación del fundamento mayor: el respeto de la dignidad humana, en todos los orbes: económico, político y social, de consuno etiquetas de garantías de garantías. Dicho de manera distinta pero unívoca, la garantía de los derechos fundamentales y su efectiva verificación como producto de la interventoría de los escogidos por el gobernante visible para destellar confiabilidad entre los coasociados. Bloque de constitucionalidad, derechos fundamentales $\mathrm{y}$ garantías fundamentales son pares en aquéllos países donde más que las expresiones legales literales importa la congruencia entre el derecho y la sociedad pretendida. Camino que asegura la axiología en su dimensión filosófica, hasta alcanzar la paz, la convivencia, la seguridad jurídica, el respeto, la solidaridad, la justicia material, la tolerancia y la dinámica fraternal en el ejercicio de una de las más sobresalientes funciones públicas de cualquier nación organizada: la administración de justicia.

Con potísimo acierto escribe Arthur Kaufmann:
Así como la dogmática jurídica es la ciencia del sentido normativo del derecho positivo válido y la sociología del derecho la ciencia de las regularidades del derecho y la vida jurídica, la filosofía del derecho tiene que ver con el derecho como debe ser, con el derecho "correcto", el derecho justo, en resumen: ella es la doctrina de la justicia. Mientras la ciencia jurídica dogmática no sobrepasa el derecho vigente y sólo critica intrasistemáticamente, la filosofía del derecho orientada transistemáticamente se interesa por el derecho vigente sólo con respecto a su valor o disvalor ... La filosofía del derecho no se diferencia, pues, de otras ramas de la filosofía en razón de ser más especial, sino en que son principios jurídicos básicos, problemas jurídicos fundamentales los que refleja, discute y, en la medida de lo posible ,responde de modo filosófico. En consecuencia un futuro filosófico del derecho tiene que ser versado en ambas disciplinas - un ideal, que naturalmente sólo puede alcanzarse en forma aproximada -, filosofía del derecho no es, entonces, ciencia del derecho, y sobre todo no es dogmática jurídica ${ }^{11}$.

\section{LA CASACIÓN: DE RECURSO A PROCESO CONSTITUCIONAL A PARTIR DE SUS FINES}

En sintonía con lo depuesto en líneas anteriores el Estado Social y Democrático de derecho como proyecto jurídico en constructo constituye uno de los fines superiores del Estado, lo que implica la constitucionalización del derecho con especial énfasis el penal, el que debe aplicarse en una dirección profundamente garantista e irrenunciable e insalvablemente garantista ${ }^{12}$, haciendo efectivo y prevalente el derecho sustancial. Una única expresión de respeto y protección de los derechos, principios y garantías tanto de lo sustancial como lo procesal. Es por eso que aparece en este estudio la denominada por Calamandrei ${ }^{13}$ labor Nomofiláctica de la casación, en el sentido de ser esta impugnación dispositiva y extraordinaria en correspondencia con uno de los fines públicos del Estado: el de la efectividad del

11 Kaufman, Arthur, la filosofía del derecho en la postmodernidad, Editorial Temis. Monografías Jurídicas, Bogotá, 1992.

12 "Gracias a esta doble artificialidad"- de su "ser" y de su "debe ser", la legalidad positiva o formal en el Estado Constitucional de derecho ha cambiado de naturaleza: no es solo condicionante, sino que ella está a su vez condicionada por vínculos jurídicos no solo formales si no también sustanciales. Podemos llamar "modelo" o "sistema garantista" por oposición al paleopostivista a este sistema de legalidad, al que esa doble artificialidad le confiaré un papel de garantía en relación con el derecho ilegitimo.

13 CFR. Piero Calamandrei, la casación civil, T II, Buenos Aires. Bibliográfica Argentina, 1962, pág. 102. 
derecho material y defensa del derecho objetivo. Hecho procesal cuya custodia se logra con el control jurisdiccional atribuido al Tribunal de casación a través de un notorio trámite procesal de control de constitucionalidad. Razón de la que desprendimos el apotegma de ser la casación como recurso extraordinario la viabilizadora de un proceso en el que se hace un juicio lógico y técnico jurídico a la legalidad constitucional de las sentencias. Un nuevo control, al control sobre el control que se hacía años atrás, pero con la gran diferencia que ahora la puesta en sede de casación de las sentencias no depende de aquellos factores que, como de procedencia, eran señalados por el legislador produciendo el quebranto a los derechos fundamentales de los ciudadanos; al ver estos obstruido el camino para llegar ciertos casos al máximo Tribunal por el prurito de la complejidad de los asuntos que debían abordar a tal sede de la justicia.

De allí que en la Ley 906 de 2004 el recurso se torna funcional a los nuevos esquemas procesales del CERTIORARI del derecho anglosajón y mexicano, un recurso de amparo para la real protección de los derechos fundamentales de los intervinientes, lo que también produce ecolalia en la sociedad en general. Significa lo anterior, como lo exponen en su tesis de especialización en derecho probatorio penal en la Universidad la Gran Colombia los estudiantes Oscar Byron Herrera Duque y Angela Viviana López Bermúdez, que en efecto con el nuevo modelo procesal de la acusación cayeron los viejos esquemas con los que se reducía la posibilidad de tramitar el recurso.

Al respecto anotó la Corte Constitucional:

Al concebir el recurso extraordinario de casación como un control legal y constitucional, se está evidenciando que la legitimidad de la sentencia debe determinarse no solo a partir de disposiciones legales sustanciales y procesales sino también de normas constitucionales en tanto parámetros de valides de aquellas. $Y$ esto en la estructura y dinámica de las democracias constitucionales es comprensible pues de la misma manera como la legitimidad de la ley, incluida, desde luego, la ley penal, no se infiere de sí misma sino de su compatibilidad con el texto fundamental; así también la legitimidad de las sentencias judiciales debe soportarse tanto en la ley como en el ámbito de validez de ésta ${ }^{14}$.

14 Corte Constitucional. Sentencia C-590 junio 8 de 2005. Magistrado Ponente Jaime Córdoba Triviño.
Así pues, control legal y constitucional significan por sinonimia de racionalidad jurídica, adecuación del instituto a referentes constitucionales. Por manera que el recurso extraordinario de casación, integra un proceso de análisis de la constitucionalidad de las sentencias provenientes de instancia en el que se verifica si son resultado de un trámite respetuoso de los derechos fundamentales.

En el derecho debe prevalecer la garantía de los derechos fundamentales y las garantías fundamentales. Postulado de integración de las notas sustanciales y procesales con arreglo a la Constitución, las cuales como se dejó evidencia en este ejercicio, deambularon en solitario promocionando serios inconvenientes para la omnicomprensión del recurso, incluyendo su sentido teórico. El proceso penal es un escenario de controversia en el cual debe prevalecer la garantía de los derechos fundamentales y las garantías constitucionales. El derecho al debido proceso constituye pilar fundamental de la actuación judicial que de no observarse torna el proceso inconstitucional y obliga al juez que advierta tal irregularidad, a declarar la nulidad en procura de restablecer los derechos quebrantados ${ }^{15}$.

Entonces, lo asuntos por resolver desde la concepción no del clásico Estado de derecho, en el que quisieron adormecerse tendencias interesadas en el statu quo, sino desde el modelo actual en su desarrollo como Estado constitucional de derecho, serían entre otros: la acción o inacción del legislativo; el desarrollo de la democracia participativa; la efectividad de los postulados y fines constitucionales; la concepción de constitución; el rol de los jueces; el lugar de los derechos fundamentales en el ordenamiento jurídico; la proyección de los derechos y alcances entre particulares y los derechos sociales; además del impacto de la globalización o mundialización sobre el constitucionalismo. Todo lo anterior puestos a prueba o analizados en sede judicial, vía control de constitucionalidad ${ }^{16}$. Recuérdese sobre esto último la presentación de la sinopsis

15 Sala de Casación Penal. Proveído del 4 de marzo de 2009

16 La omisión legislativa en Colombia: Entre el control constitucional y el activismo judicial. Artículo de los doctores: Héctor Elías Hernández Velasco y Orlando Pardo Martínez, financiado por la universidad Industrial de Santander y publicado en el tomo IV de Derecho Procesal Constitucional Editores Ltda, capitulo XVII. Pág. 395 y 396. 
legislativa de los fines del proceso penal en Colombia desde 1971.

Por manera que la interpretación constitucional es la reivindicación axiológica de lo jurídico. La doctrina constitucionalista actual adopta un particular modelo constitucional a defender, en el cual La Carta se aplica en razón o en función de su particular contenido y no dependiendo de su desarrollo legal, en ese sentido no será el legislador o la ley la fuente básica o definitiva para el operador de justicia o valor contenido en la Carta, ponderado racionalmente por el juez. En nuestro caso, la casación, a partir de la impoluta aplicación de los principios superiores subyacentes en los fines del instituto procesal, es decir, su fundamentación filosófica. De tal forma se rebasa el modelo ius positivista clásico, en el sentido en que lo que justifica la decisión no será la norma o ley necesariamente, ni su cadena jerárquica, sino la remisión expresa al texto constitucional; el cual le permite un acceso directo al discurso moral-axiológico que esta contempla, lo cual implica una reconsideración en la conexión entre el derecho y la moral. En tal medida se abandona la concepción de un modelo descriptivo de la norma constitucional, es decir, se supera esa perspectiva descriptiva para pasar a un modelo vinculante - prescriptivo- modelado hacia su eficacia material. Por ello, la nueva interpretación jurídica es la que lleva consigo la transformación del mero rito procesal discursivo del recurso extraordinario a un verdadero análisis de la constitucionalidad de una sentencia, que debe arrimar además de las notas de presunción de acierto y legalidad, por aquello de la jerarquía, toda una carga argumentativa de la demostración del respeto por las guardas constitucionales. Esto implica cambios novedosos en el control de constitucionalidad por parte del Tribunal especializado, la administración de justicia propiamente dicha y los efectos peculiares de las sentencia con relación a los corolarios derivados de la extracción de las esencias constitucionales y, finalmente, la hermenéutica jurídica - la ponderación ${ }^{17}$.

Así, no es la producción de seguridad lo que constituye el carácter racional de la jurisprudencia, sino el cumplimiento de esas condiciones y criterios o reglas provenientes de las entrañas de la Constitución. En este trabajo

17 Ibídem se ha querido dejar ello en claro con el báculo de la filosofía, la cual atiende la razón en su natural concepción tanto humana como jurídica. Por eso mismo su presentación histórica y algo sistemática hace fluir el concepto de la nueva argumentación jurídica de cara a la protección de los derechos y las garantías constitucionales en sede de casación. En la que, así como el amor desde lo sentimental hace posible la unión perfecta, en el caso del derecho la justicia se logra con el matrimonio racional y humano de lo sustancial con lo procesal, es decir, las configuraciones de los derechos fundamentales con el de las formas procesales o garantías; convirtiéndose cada uno de estos elementos en convocados eviternamente para hacer posible el manejo de un concepto de justicia que satisfaga las expectativas de un modelo que, sin lugar a dudas, es más conveniente que aquellos cuyos resultados dejaron ver demolido el derecho y casi muerta la fe y la esperanza de los coasociados.

En tal virtud, no hay que infravalorar la función de la teoría del discurso jurídico racional e ius filosófico como definición de un ideal Como tal ideal apunta más allá del campo de la jurisprudencia, los juristas pueden ciertamente contribuir con dignidad y decoro a la realización de la razón y de la justicia, pero esto, en el sector que ellos ocupan, no pueden realizarlo aisladamente. Ello presupone un orden social racional justo $^{18}$.

\section{CONCLUSIONES}

Verificado cómo la norma implantada en vigencia de la Constitución de 1886, destinada al establecimiento de los fines de la casación, pasó a la órbita del texto constitucional de 1991, señalando al efecto la efectividad del derecho material, la unificación de la jurisprudencia, la reparación del daño inferido a las partes con la sentencia y la protección de las garantías fundamentales; tal acontecimiento significó para el derecho interno que se siguiera atendiendo el contenido literal del precepto en detrimento de la validez jurídica y política de algunas decisiones tomadas en sede extraordinaria.

Razón por la cual por algún tiempo siguió imperando el categórico de las garantías

18 Alexy, Robert. Teoría De La Argumentación Jurídica, Traducción de Manuel Atienza e Isabel Espejo. Pág. 279 y 280. 
fundamentales sobre el de los derechos fundamentales. Situación que por desatender el contenido constitucional del artículo 230 en el sentido de que los jueces en sus decisiones deben someterse al imperio de la ley - constitucional -, invita a revisar la actitud judicial frente a la comunidad jurídica nacional, académica y progresista del derecho. Filosofía del derecho, no es ciencia del derecho, tampoco dogmática jurídica.

Con ello, situaciones de la magnitud advertida, determinaron y guiaron la mirada filosófica de los juristas para medir hasta dónde tales sucesos obstaculizaron en gran parte el ingreso del prometido Estado social de derecho al seno de la sociedad colombiana. De un lado, porque la administración de justicia siempre constituirá una de las principales funciones públicas monopolizada por el Estado y, de otro, porque si la fundamentación de aquel estriba en el respeto de la dignidad humana, ello denota que por la naturaleza del proceso penal, lo más lógico es pensar que las actuaciones penales deontológicamente, sin excepción, han de mostrarse como uno de los elementos de mayor credibilidad ante la ciudadanía, a fin de que esta no se sienta tratada de manera diversa a la ordenada por la ley mayor.

En ese orden de ideas fluye claro que actualmente en Colombia los fines de la casación son el fundamento filosófico del recurso y, por tanto, el trámite previsto para su desarrollo es un auténtico proceso constitucional en el que se pesan los distintos factores que, llamados a actuar armónicamente en conjunto, garanticen el paso constructor del Estado Social de derecho con base, se insiste, en la aplicación de la justicia constitucional. Con base en la Constitución de 1991 el viejo teorema debió rápidamente variar abriendo camino al nuevo que, como se demostró, no es otro que el de la validez en la apropiación de los derechos fundamentales por parte de todos a favor de los fines estatales y sociales de la casación, la que no sobra recordar, fue parida por un movimiento revolucionario como conquista en oposición al ejercicio omnímodo del poder y de los abusos de quienes lo ostentan.

Por manera que con el nuevo Código de Procedimiento Penal - inclusorio del sistema acusatorio en Colombia - se pone a las claras que efectivamente fue necesario valerse de la norma por la norma para que se viera la casación como un control constitucional, respetuosa del bloque de constitucionalidad y de los derechos fundamentales. Discurso en nada especulativo, amén a que de conformidad con la pluma del legislador, se otea que lo protegido hasta ahora como principal - norma legal y garantías fundamentales- queda inexorablemente relegado por lo dispuesto matricialmente por la Constitución. Elemento de juicio que permite asegurar sin ambages que perdimos más de una década, al resultar obstaculizada la aplicación plena de los mandatos constitucionales, en una de las fortalezas del poder del Estado, cual es la administración de justicia en lo penal. Por lo demás, entiéndese el impacto trascendente de algunas decisiones que ha venido tomando nuestra Corte Suprema de Justicia en marcha el nuevo código de procedimiento penal.

Por todo lo anterior, es indispensable que los jueces no pierdan el norte despistándolo con la mera lógica de los fallos, sino que atiendan con longanimidad y discreción los valores fundamentales contenidos en la Constitución y en los tratados públicos sobre derechos humanos, las garantías penales y procesales, paralelamente con los ideales de la comunidad jurídica nacional e internacional con referente inamovible en la paz, la justicia social, la dignidad humana, la libertad, la igualdad, la solidaridad etc. Es una luz que entra por las mañanas y parece que en verdad es un desierto.

\section{PROPUESTAS}

Para quienes participamos con altivez en el mundo de la academia, toda propuesta tiene un común denominador cuyo fundamento estriba en la esencia de aquella, de tal manera que de entrada queden aislados todos los factores que equívocamente han focalizado una división inmisericorde entre los seres humanos, en el entendido que el conocimiento se puede estratificar.

Con esta liminar reflexión así como el amor, el más humano de los sentimientos, requiere del valor para la demostración de su real existencia y de la renuncia a muchas de las fuentes materiales que lo ruinizan, en el caso del derecho con visión antropocéntrica, tal predica es incuestionable, amén a que cuando el ser humano es el eje referente, ello demanda, en todas las ciencias, que los conceptos atados a esa materialidad 
desaparezcan. Todo debido a que, si como ha ocurrido con el derecho positivo, éste se guarnece como fortaleza en el contenido literal de las normas, sus consecuencias no dejan esperar el espanto que produce el reemplazo del hombre por las obras que, a pesar de ser de él mismo su creador, no garantizan el desarrollo de la disciplina jurídica y menos el del progreso; al que hemos sido invitados todos desde el momento en que fuimos concebidos y por ende integrados al concierto universal de la humanidad, la que despacha leyes incontrovertibles por parte del hombre, por más recalcitrante que sea; una, la principal, la del respeto de la dignidad humana.

Es cierto, la esclavitud no ha desaparecido ni desaparecerá, pero no menos veraz que mientras sigamos alimentando su vientre de ultraje, el derecho cada vez será más longincuo de los cuadros de razonabilidad.

De donde surge claro que frente a todas las vicisitudes de la vida, las respuestas de la criatura humana deben armonizar con la inteligencia, consciencia, pensamiento juicioso, memoria y sensopercepción, no con el instinto de la refrigeración de las tendencias o del acomodo a pilares de suyo desuetos o destronados por la razón, que se explica a sí misma.

Sin duda, la humanización del derecho no perturba la autoridad, contrario sensu, la engrandece y fortifica, en la medida en que las decisiones que son arbitrio individual, gobernado por determinaciones sin ninguna instancia posible de validación intersubjetiva, son una forma de esclavitud sin remedio, al tiempo que si la decisión tiene fundamento racional y alguna fuerza de convicción general, estamos frente a una auténtica administración de justicia, capaz de lograr su aceptación de la comunidad. Entonces es menester superar todas las falencias que acusan a un sistema como inoperante e inaplicado. No es entendible a esta altura de la historia que por ejemplo alguien llamado a decidir, deje de hacerlo, parapetado en que la función consiste en acumular foliaturas, por la sombra vigilante del órgano de control, o que el administrador de justicia lastime su naturaleza dándole paso a la descarga de lo hecho por otros, por el temor vacilante de incurrir en una maniobra prevaricadora.

La filosofía del derecho tiene otro referente fundamental que es el componente decisorio del derecho, porque quien crea normas, quien las aplica, quien decide obedecerlas o no, lleva a cabo decisiones. Por manera que cuando el texto constitucional advierte su báculo en el respeto de la dignidad humana, el carácter pluralista e interdisciplinario del derecho, no puede frenarse por las rejas reclusorias del derecho positivo puro, sino que nace la alternativa del buen juzgar de acuerdo con las orientaciones de la Carta Mayor.

Así las cosas, es importante, urgente, indispensable e inaplazable que el criterio constitucionalista se imponga en las decisiones racionales y judiciales, para que la jurisprudencia dé espacio a la iuris - sofía. Pero ¿Cómo lograrlo? Solo a partir de los procesos de formación $\mathrm{y}$, no me refiero únicamente a los niveles universitarios; a todos. Es decir la etapa de la infancia, la pubertad, la juventud, la adultez, la vejez, la ancianidad. Dicho de otra manera, no la academia vista como el ladrillo lacado; sino como el ámbito donde se aprecia el pulular de todos los coasociados, por suerte que aceptemos que la paz no se logra a punta de fusil ni de interpretaciones restringidas de las normas, sino con la educación y una hermenéutica basada en la argumentación jurídica.

Todo lo anterior, inalcanzable de no crearse el compromiso reciproco de los colegiados, las asociaciones, los gremios, la academia y las distintas personas facturadas dentro de esquemas pluralistas, de cara al intercambio racional de ideas con aquellos cuyas decisiones, se espera, sean fieles al Estado Social de derecho, garantizado a partir de 1991, pero, hecho aciago, no aplicado por distintos intereses.

Tarea nada fácil. Empero, la historia judicial de Colombia espera de la convicción y el denuedo de los verdaderos amantes del derecho, la revolución ideológica que viabilice el rompimiento de la mera garantía normada, por la de la aplicación plena de los derechos fundamentales.

Colombia es un país que desde el 12 de octubre de 1492 ha vivido engañado y ahorcado por los eufemismos. Hay dobles lógicas contradictorias por doquier, aporías ni se diga. ¿Solución?, pongámonos de acuerdo a través de un consenso espontáneo, donde, por ejemplo, desnudemos y reconozcamos nuestros errores del pasado, si lo hizo la iglesia católica ¿por qué no quienes también trabajamos una disciplina ajena a los 
juicios espirituales? El caso de los verdaderos abogados.

Apliquemos con constancia la filosofía del derecho en las facultades universitarias, empezando por la congruencia entre el discurso con la obra, patrocinemos el intercambio racional de ideas, sometamos los cambios desde la base para que la confluencia se logre en el punto intermedio con los que ejercen materialmente el poder, fomentemos el estudio y análisis de nuestra historia, pero, y, sobretodo, venzamos el moralismo con el instrumento eficaz de la consciencia sobre la crisis moral que, sin hesitación, constituye el mejor elemento de juicio de cara a la consolidación del respeto de la dignidad humana como vehículo conductor hacia el Estado Social de derecho.

Colofón de lo anterior, mi indicción a la comunidad en general a ser partícipe activa de su propia historia, sin temores, sin miedos, sin rencores, con valor, con respeto, con tolerancia, con firmeza y dignidad. Ajenidad total a la irredención, a la plutocracia, a la endogamia, a la pacatería, a la mojigatería, a la genuflexión y a las distintas actitudes que terminan por mostrar un pueblo constructor de su ruina. No se pierda de vista que las $4 / 5$ partes de la humanidad, subyacemos arrasadas por el imperio de la 1/5 porción, no en tanto, una y otras, constitutivas de la población mundial, esa que debe despertar con el talento del respeto, la solidaridad, la tolerancia y el pluralismo, factores sin los cuales el derecho es represor, no emancipador, menos liberador.

La casación es una conquista revolucionaria y de apertura a la emancipación de los pueblos, a fin de que estos se precien algún día de haber obtenido solo con el uso de la razón, la libertad a través de la filosofía ilustrada e iluminada por el respeto a los derechos fundamentales, los cuales no tienen edad, signo, logotipo, partido, estrato o cualquier otro disparatado elemento, de los muchos que disgregan a las criaturas sin rumbo fijo.

Ante la súplica de piedad, responded libertad, ante la de legalidad, replicad justicia. A fin de cuentas dentro de cada criatura siempre hay un ser decidido, menester encontrarlo. 


\section{BIBLIOGRAFIA}

- Alexy, Robert. Teoría De La Argumentación Jurídica, Traducción de Manuel Atienza e Isabel Espejo. Pág. 279 y 280.

- Cadena Lozano, Raúl. Código Penal y Código de Procedimiento Penal. (Concordados y actualizados suplemento legislativo). $3 \mathrm{Ed}$. 1996. pág. 203.

- CFR. Piero Calamandrei, la casación civil, T II, Buenos Aires. Bibliográfica Argentina, 1962, pág. 102

- Código procedimiento penal actualizado. 2011.

- Corte Constitucional. Sentencia C-590 junio 8 de 2005. Magistrado Ponente Jaime Córdoba Triviño.

- Derecho procesal constitucional, tomo IV, Editores Ltda. Libro resultado de investigación. Pág. 130.

- Díez Ripollés, José Luis. Práctica y teoría la racionalidad de las leyes penales. Trotta. Bogotá, D.C. 2003. pág. 135 - 136.

- Ferrajoli, Luigi. El garantizo y la filosofía de derecho. Departamento de publicaciones de la Universidad Externado de Colombia. Bogotá, D.C. 2000. pág. 177 - 178
- Introducción a la filosofía. Segel Michelin Pastor. Academia Ministerial Logos.

- Jaramillo Velez, Rubén. Problemática actual de la democracia. Jurídicas G. Ibáñez C. Ltda. Bogotá, D.C. 2004. pág. 57-58.

- Kaufman, Arthur, la filosofía del derecho en la postmodernidad, Editorial Temis. Monografías Jurídicas, Bogotá, 1992.

- La omisión legislativa en Colombia: Entre el control constitucional y el activismo judicial. Artículo de los doctores: Héctor Elías Hernández Velasco y Orlando Pardo Martínez, financiado por la universidad Industrial de Santander y publicado en el tomo IV de Derecho Procesal Constitucional Editores Ltda, capitulo XVII. Pág. 395 y 396.

- Nuevo Código De Procedimiento Penal, Edición actualizada. 2003. pág. 232.

- Ortega Torres. Código Penal y Código de Procedimiento Penal. Temis. Bogotá, D.C. 1988. Pág. 124.

- Proyecto De La Ley Estatutaria. Pág. 52.

- Sala de Casación Penal. Proveído del 4 de marzo de 2009. 